\title{
PROCESSOS IDENTITÁRIOS E RELAÇÕES PATRÃO-CLIENTE ENTRE OS KAIOWA*
}

\author{
Alexandra Barbosa da Silva
}

\begin{abstract}
Ser um indígena não significa que você possui uma cultura indígena separada. Em vez disso, provavelmente significa que em alguns momentos, em algumas ocasiões, diz-se: "Essa é minha identidade étnica. Este é o grupo ao qual desejo pertencer" (Barth 2005:18-19).
\end{abstract}

\section{Introdução}

As proposições de Barth (2000a [1969], 1987, 1993, 2000b, 2000c), Wolf (1982) e Hannerz (1992) nos indicam que os fluxos culturais e as interconexões devem ser tomados como ponto de partida para nossas análises; tentar definir especificidades culturais enquanto totalidades dadas a priori iria, assim, na contramão da percepção de que estas são, antes, o resultado de escolhas, de transações de materiais culturais (conhecimentos, valores, ideias etc.) feitas pelos sujeitos - em grande parte do tempo, observo, emolduradas em relações de poder - e, enfim, dos recortes e ordenamentos desses materiais feitos pelos mesmos sujeitos socialmente organizados. Deste modo, são geradas identidades sociais (incluindo as de caráter étnico). Estamos aqui em face da distinção feita por Barth entre cultura e organização social, tendo ele concluído que, por um lado, as identidades são continuamente configuradas em contextos específicos e, por outro, há um processo de conformação de padrões culturais em decorrência da articulação de intersubjetividades, uma vez que, a rigor, cada indivíduo possui uma cultura singular (Barth 2005).

Tal conjunto de proposições será útil para analisarmos as dinâmicas socioculturais que têm base na vida de indígenas kaiowa contemporâneos em Mato Grosso do Sul. Assim, de início, pergunto: como olhar a vida desses indígenas sem considerar os não índios no processo de colonização desse estado da federação? Fatos de um passado recente e do presente revelam que a relação com aqueles que se estabeleceram em terras de ocupação 
tradicional deste povo, vindo também a explorar a mão de obra indígena, tem moldado boa parte das atividades, dos atos, dos hábitos etc. destes mesmos indígenas.

Com efeito, constata-se ser impossível pensar tais indígenas sem considerar os não indígenas, de modo que nos encontramos com as proposições de Gluckman na análise das relações entre zulus e europeus. Ocorre apenas que, na perspectiva de interdependência (em "oposição desigual") entre esses grupos, não obstante sua refinada reflexão, a observação de que os comportamentos são "socialmente definidos" (Gluckman 1987 [1940]:243) deixa em aberto como isso ocorreria. É evidente, penso, que tais padrões são resultado das interações entre as pessoas, conforme propôs Barth, sendo relevante a sua noção de "estrutura da interação". No texto de 1969 encontramos:

A persistência de grupos étnicos em contato implica não apenas a existência de critérios e sinais de identificação, mas também uma estruturação das interações que permita a persistência de diferenças culturais (Barth 2000a [1969]:35).

E ainda:

[...] A interação tanto requer como gera certa congruência de códigos e valores, em outras palavras, uma similaridade ou comunidade cultural (:35).

$\mathrm{O}$ autor possivelmente tinha em mente o "modelo gerativo" que propusera em Models of social organization (1966), mas sua proposta teórico-metodológica ganhou adensamento com a noção de "estrutura da ação social". Esta é pensada a partir da relação entre os atos dos indivíduos (que são diferencialmente imbuídos de cultura e posicionados), os eventos que estes atos engendram e as experiências geradas pelas interpretações desses atos e eventos pelos próprios indivíduos, produzindo-se, assim, estoques culturais específicos (ver Barth 1993:173, 2000c).

Cabe ainda considerar uma discussão sobre a construção de redes de relações sociais. Aqui se coadunam a célebre proposta de Barnes (1987) sobre o tema e novamente Barth, num artigo seu de 1978, no qual analisa a construção das redes. Nesse processo, um ponto importante deste último texto para meus propósitos é a distinção feita entre a adscrição e a escolha dos sujeitos, identificadas, cada uma e respectivamente, com "sociedades não ocidentais" e "ocidentais" (Barth 1978:182). No tocante a Barnes, por seu turno, ao propor serem as redes sociais formadas com base na possível relação com desconhecidos, ele se fundamenta numa diferenciação entre "sociedades de pequena e de grande escala". Definindo estas últimas como 
"sociedades tribais", afirma que nelas não seria plausível uma análise em termos de rede social, nem haveria espaço para "relações idiossincráticas de amizade com estranhos ou de patrão-cliente" (Barnes 1987:187); tais características seriam prerrogativa das "comunidades urbanas populosas".

Como destaquei anteriormente (Barbosa da Silva 2009), à parte a crítica de que nada indica que "nas sociedades de grande escala" (se aceitarmos este termo) as coisas se passem conforme ele descreve, a ênfase de Barnes propositalmente parte de uma diferenciação esquemática e reducionista, concebendo unidades sociais polarizadas, não obstante uma breve ressalva sua de que "entre os dois extremos haveria muitos tipos intermediários" (Barnes 1987). Ora, vê-se que a ideia de pessoa "desconhecida" do grupo pressupõe uma unidade eternamente fechada em si, algo não sustentável na grande maioria dos casos. ${ }^{1}$ Assim, contrariando o que este autor afirma, no caso aqui em foco, a relação patrão (não índio) / cliente (índio) se impõe como um fato, que será analisado. Uma bibliografia sedimentada em patronagem e compadrio, portanto, fornecerá base para a reflexão, considerando-se seus alcances e limites explicativos. Entende-se que a compreensão das relações interétnicas na região em pauta (bem como dos conflitos delas decorrentes) é beneficiária exatamente desta reflexão, que porém, até o momento, tem sido pouco explorada em termos propriamente acadêmicos.

Além de seus "patrões", as redes de relações kaiowa incluem outros não indígenas, de modo que o que objetivo analisar é como em meio ao desenrolar das interações destes indígenas são desenvolvidos processos identitários, sendo a adscrição étnica uma das possíveis - ela própria devendo ser focada. ${ }^{2}$ Porém, ela não é a única. Ver-se-á que a identidade cuja base é o grupo doméstico e sua moralidade se reveste de extrema importância. Neste quadro, uma dicotomização entre adscrição e escolha não é útil, sendo tênue a linha que define os limites entre um e outro destes conceitos. Mas concordando com Boissevain (1987), vê-se que os atores sociais lidam com as normas e/ ou valores que lhes servem de parâmetro, adequando-os, ajustando-os de acordo com seus interesses a partir de um leque de possibilidades que cada situação coloca. É evidente, ainda, que o quadro de distribuição de poderes entre esses atores é fundamental para os limites desta margem de manobra.

Em sua estruturação, o presente estudo inicia-se com um breve desenho da ocupação não indígena no sul de Mato Grosso do Sul e do processo de territorialização (Oliveira 2004) ${ }^{3}$ impingido aos Kaiowa. Na sequência, focarei como são delineados distintos modos de ser e de viver (o "do Kaiowa" e o "do não índio"), a partir dos quais as relações com os brancos são efetivadas e avaliadas. A relação com o patrão (ao mesmo tempo "matéria-prima" e resultado desse procedimento cultural) será abordada a seguir, lançando-se 
luz sobre como têm sido delineadas suas bases e as expectativas recíprocas. Já com os dados e os argumentos desenvolvidos, farei uma síntese sobre a conformação das identidades, tendo importância a noção de "comunidade moral" apresentada por Bailey (1971). Enfim, em conclusão, encontraremos um fator já ressaltado por Max Weber (1983): a relevância dos processos políticos na conformação dos grupos (étnicos) e das identidades.

\section{A ocupação não indígena e o processo de territorialização}

Nas relações envolvendo os Kaiowa (bem como os Nandéva) ${ }^{4}$ na região, aquelas com os "patrões" são importantes e tão antigas quanto o estabelecimento da exploração da erva-mate. Após o fim da Guerra do Paraguai (em 1870), num primeiro momento, a Companhia Matte Larangeiras passou a atuar no território de ocupação desses indígenas, explorando com exclusividade a erva-mate e a mão de obra nativas. Posteriormente, cooperativas pluralizaram a presença de "ervateiros", com os indígenas passando a conhecer os corolários da relação com "patrões".

Preocupado com o controle do território no pós-guerra, em 1910 o Estado criou o Serviço de Proteção aos Índios (SPI) que, entre 1915 e 1928, reservou oito pequenas terras para os Kaiowa e os Nandéva, liberando espaços para a ocupação não indígena. ${ }^{5} \mathrm{O}$ órgão então, paulatinamente, conduziu as famílias indígenas para estas reservas, retirando-as dos extensos espaços que ocupavam, com uma morfologia social (Mauss 1993a) específica: uma distribuição difusa no espaço, a partir de cursos d'água.

A titulação das terras engendrou grandes fazendas, sobrepostas aos territórios indígenas, além de uma presença mais marcante dos brancos, que passaram a ver naqueles uma mão de obra abundante, atuando para mantê-la. De fato, prestar serviços para o patrão foi o que permitiu a um grande número de indígenas permanecer nas terras. A derrubada do mato para a instalação das propriedades foi feita maciçamente por estes mesmos indígenas, sendo que, nos anos 1970, a mecanização da produção fez cair enormemente a demanda por estes braços. ${ }^{6}$ Em contrapartida, produziu-se um inchaço populacional nas reservas (Thomaz de Almeida 1991). Porém, para todos os trabalhos para a manutenção das fazendas, tais braços continuaram em medida significativa sendo indígenas, sempre na sua configuração familiar: as mulheres e as crianças exercendo os serviços domésticos e os homens, nos demais tratos, com ambos realizando também as tarefas para a manutenção do próprio lar. Logo adiante me deterei sobre tal ponto, mas para isto é fundamental ver como se dá a organização social, sobretudo a 
doméstica, entre estes indígenas. A partir dela se geram formas de percepção e avaliação extremamente importantes de serem analisadas para os processos identitários, foco deste estudo.

\section{Modos de ser e de viver em confronto}

Ao falar em organização social é necessário precisar sobre o que estamos discorrendo. Entre estes indígenas duas categorias têm singular importância. Uma, recorrente na literatura, é te'yi (v. Meliá et al. 1976; Thomaz de Almeida 1991; Pereira 1999; Mura 2006; Benites 2012). A outra, utilizada exclusivamente por Benites (antropólogo kaiowa), é hente (Benites 2012). Ambas referem-se ao que tem sido definido como "família extensa" — aquilo que Evans Pritchard chamou de "família indivisa" (1982). Trata-se do grupo conformado a partir de três gerações, podendo agregar outros indivíduos (consanguíneos ou não consanguíneos). Especificamente, a noção de hente é fluida, com as pessoas podendo ser incorporadas ou não no discurso e na ação dentro de um círculo de parentes, dependendo do contexto de interação (v. Benites 2012). Em termos literais significa "gente" — no sentido de "a gente [o pessoal] que faz parte de uma mesma família". ${ }^{7} \mathrm{Na}$ prática, a hente é definida por um sobrenome a qualificar todos os seus integrantes, de modo que se tem, por exemplo, "Ximenes kuera" (kuera é uma partícula de plural; assim seria: "os Ximenes") ou "Benites kuera" ("os Benites"). De todo modo, a unidade sociológica cuja ação de seus membros é mais efetiva e intensa no dia a dia é o grupo de três gerações (para os Kaiowa, o te'yi).

Tal grupo, em termos econômicos, se constitui ao mesmo tempo como de produção e de consumo. Há, contudo, outros aspectos fundamentais, que perpassam e dão vida às interações em seu interior — como a educação das crianças e a transmissão de conhecimentos, valores, crenças etc. - com cada integrante do te'yi tendo definida uma série de obrigações recíprocas. As relações no seio do te'yi se configuram a partir dos pares relacionais marido e mulher, pais e filhos, avós e netos, irmãos entre si, sogros e genros, e cunhados entre si, sendo a observância das obrigações algo fundamental para a manutenção dos seus laços. Define-se, em consequência, uma cooperação e uma interdependência entre tais integrantes que abrangem, em um complexo indivisível, os aspectos econômicos, de socialização e aprendizagem, afetivos etc. Se nos remetemos à nomenclatura do parentesco, isto corresponde ao que é chamado household (v. Wilk \& Netting 1984; Wilk 1984, 1997). ${ }^{8}$

Há ainda outros fatores a influenciarem a delimitação de um determinado grupo de parentes, ou seja, o cotejo e o confronto constantes em 
relação a outros grupos de igual natureza em sua composição. Tonico Benites (2012) delineia bem o jogo relacional que faz com que, para além dos laços de parentesco, determinados valores, interesses e expectativas sirvam como parâmetro para as pessoas se reconhecerem e se autoafirmarem como pertencentes a um grupo. Este tem como referência um casal mais idoso, à cabeça de uma parentela de três ou mais gerações (respectivamente chamados tamõi e jari, e tamõi guasu e jari guasu). Tomando, por exemplo, num grupo que tem José Benites e Emília Romero Vargas (avós de Tonico) como tamõi guasu e jari guasu, cada um dos filhos deste casal será, por sua vez, um tamõi ou uma jari. Com exceção dos próprios José e Emília, cada um dos demais membros, quando em contraposição a outro grupo de igual conformação, se nomeará "Benites kuera" (ou seja, "os Benites" ou "gente do Benites").

Para a boa (con)vivência do grupo, o comportamento ideal se fundamenta nos cuidados que cada membro deve ter para com os demais. O mito sobre a criação do povo kaiowa apresenta um modelo para os comportamentos individuais, em termos morais e éticos. Nesta narrativa, uma série de percalços deve ser vencida até o desfecho de uma harmonização plena entre os membros do te'yi que deu origem a todos os demais (e atuais) te'yi kaiowa - e que são tidos como parentes (os primordiais) deste povo. Ele é constituído por Nane Ramoi (Nosso Avô), Nande Ru (Nosso Pai), Nande Sy (Nossa Mãe), e dois irmãos homens, filhos deste casal: Pa'i Kuara (o Sol) e Jasy (a Lua). ${ }^{9}$ A completar esse quadro está a relação formada por "cunhados", muito importante e que foi explanada de modo particular na contemplação de um casamento interétnico, incorporando-se figuras originárias do panteão cristão, mas cujas divindades são plenamente kaiowa. ${ }^{10}$

De modo resumido, a narrativa sobre o surgimento do primeiro homem branco é a seguinte: no espaço-tempo das origens (Áry Ypy), uma filha de Pa'i Tani (outro nome para Nane Ramõi), chamada Tupãsy Ka'acupe, se casou com um homem chamado San José. Os filhos de Pa'i Tani trataram-no como cunhado, dele esperando reciprocidade. Ocorre que San José não correspondia. Certa vez, seus cunhados quiseram avisá-lo de que em um determinado lugar haveria lançamento de raios para purificar o ambiente. Ele, porém, não quis ouvir a mensagem e foi atingido fatalmente por um dos raios, ficando reduzido a cinzas. A esposa suplicou ao pai que o revivesse e ele a atendeu. Mas como as cinzas são brancas, San José adquiriu esta cor. O casal teve muitos filhos, todos de igual coloração, dentre os quais está Jesus Cristo. Este seria o "princípio" do homem branco e das suas características - entre as quais a rejeição a ouvir, a dialogar, e a falta de reciprocidade para com os Kaiowa. 
Sempre que se apresentar uma situação de desentendimento no seio de um te'yi, essas narrativas serão contadas por alguém, visando revertê-la. Assim, elas funcionam como um parâmetro para os indivíduos pensarem o universo como ordenado a partir desta unidade social: o te'yi. Há ali a prescrição de comportamentos ideais para os indivíduos, que na prática vai encontrar maior ou menor realização. Mas a força que atua sobre seus membros é um imperativo, tornando-se extremamente difícil escapar às obrigações e à cooperação que lhe dão sustento — num modelo eliasiano (Elias 1991) de configuração — o que constitui forte base para a conformação da moralidade destes indígenas.

Ressalte-se que não é por essencialismo que as pessoas privilegiam as relações no seio deste grupo. Como Wilk e Netting (1984) indicaram, "as ideias, normas e valores das pessoas, concernentes à sua vida doméstica, são um importante constrangimento aos seus comportamentos" (:2). Lembremos que este é o grupo de referência primário das pessoas e romper com suas expectativas é correr o risco de ser dele proscrito.

A relativa autonomia de cada te'yi - materializada inclusive espacialmente, mantendo-se o máximo de distanciamento possível entre as residências de grupos distintos - faz com que ele seja a unidade fundamental de referência de seus integrantes. É também o ponto de partida para o estabelecimento de relações mais amplas, isto é, comunitárias, o que ocorre por adensamento das relações desses integrantes, de modo primordial através de alianças matrimoniais exogâmicas.

A narrativa que inclui San José, observamos, descreve os Kaiowa e os não indígenas enquanto seres que foram na origem aparentados entre si por laços de afinidade. ${ }^{11}$ Mas ao mesmo tempo remarca uma distinção, que é fundada em termos comportamentais - para além da cor da pele. A dificuldade de interagir, a partir desta distinção, revela a percepção de uma diferença com efeitos importantes para o estabelecimento das relações (no seio do te'yi, mas não apenas). A análise que ali subjaz parte de uma avaliação claramente moldada em experiências, mantidas também com não índios e de observação dos comportamentos destes. As trajetórias (individuais e coletivas), as experiências dos sujeitos indígenas e suas reflexões sobre estas, aliadas às sínteses explicativas e morais realizadas pelos xamãs (ñanderu), constituem um corpus de entendimentos que permite o estabelecimento de padrões comportamentais - no caso, distintos, que são então tomados como contrapostos. Tais padrões, é de se ressaltar, são também transmitidos no tempo através de gerações, inclusive criando-se estereótipos, a funcionarem como orientadores para as interações dos sujeitos..$^{12}$ Dito de outro modo, tem-se um processo de conformação de distintos modos de ser, em uma clivagem que é, de fato, de caráter étnico. 
Como bem focou Benites (2012), ele próprio um kaiowa, cada te'yi é visto como portador de um estilo comportamental particular (um teko, isto é, um modo de ser), que o caracterizaria e diferenciaria enquanto grupo em relação aos outros, produzindo-se assim uma pluralidade de teko (o teko laja kuera). Trata-se de uma diversificação a partir de modos diferentes de entender e de organizar os mais diversos elementos culturais, assim como de empreender atividades práticas, o que tem consequências para o comportamento dos indivíduos e suas identidades. ${ }^{13}$ Uma forma de expressar tal diversidade pode ser vista no uso dos pronomes para a primeira pessoa do plural: "ñande" e "ore". No primeiro caso, trata-se de um "nós" que é exclusivo e, no segundo, inclusivo, isto é, a partir de um determinado grupo, ego utiliza "ñande" quando se refere ao grupo como um todo, mas utilizará "ore" quando quiser restringi-lo, dele excluindo pessoas. De qualquer modo, importa ressaltar que esses diversos "modos" (teko) são tidos sempre como diversos do "modo de ser do branco" (o "karai reko") e a ele opostos. Tem-se, portanto, um (imaginado e constantemente construído) "ñande reko" ("nosso modo [kaiowa] de ser").

No que tange à definição de potenciais parentes (ou seja, nas alianças por afinidade), a narrativa que contempla San José indica que o modo de ser do branco não faz dele o mais apropriado de acordo com este intuito. Isto não significa que não ocorram absolutamente casamentos interétnicos; estes, porém, são numericamente pouco expressivos. Em se tratando de uma região de fronteira, há casos de casamentos de mulheres (muito mais do que de homens) kaiowa seja com um "brasileiro", seja com um "paraguai" — conforme são definidos pelos indígenas os indivíduos não indígenas de tais nacionalidades. Cabe observar que no processo de colonização dessa região o estabelecimento das fazendas concentrou um contingente de trabalhadores com condições socioeconômicas comuns. Inicialmente, pela aproximação devida com o contexto rural de vivência comum e do compartilhamento da língua guarani, houve aproximação entre os indígenas e os cidadãos paraguaios, estes atuando como capatazes nas fazendas e intermediários entre os índios e seus patrões. Posteriormente, houve a incorporação de peões já brasileiros. Hoje em dia, nas periferias das cidades nos entornos das aldeias, há bairros que concentram uma população de brasileiros e de paraguaios humildes. Tal vivência histórica e o contexto atual permitiram e permitem o compartilhamento de certas experiências por essas pessoas, considerando-se também o bilinguismo (guarani e português) de grande parte dos Kaiowa.

Num grupo com tal tipo de união matrimonial constata-se que o indivíduo não indígena, internamente ao grupo, será visto e remarcado como tal apenas se não corresponder às expectativas de obrigações e reciprocidade. 
Para o caso já de filhos, é importante observar que a filiação entre os Kaiowa é reconhecida por bilateralidade. Assim, na T.I. Jaguapiré vive um rapaz cujo pai era paraguaio, mas que cresceu com a mãe e seus avós maternos, numa família das mais prestigiosas da aldeia, de modo que sua identidade kaiowa de modo geral não é contestada. Por outro lado, é possível que, sempre que seja necessário remarcar adversidade ou diferença em relação a este grupo, integrantes de outro te'yi com quem são mantidas relações de oposição apontarão a origem não indígena daquele indivíduo.

Extraindo daqui conclusões, vemos que: o estilo de vida e as experiências que são comuns, a partir de atividades desenvolvidas e assuntos que preenchem o cotidiano e orientam as atenções, sob condições materiais muito semelhantes (em um contexto de lida "rural"), bem como o domínio comum de uma língua, são relevantes para permitir uma aproximação entre indígenas e não indígenas, possibilitado mesmo casamentos. Concomitantemente, constata-se que o respeito às obrigações no interior do te'yi (grupo doméstico) funciona como um valor que é, ele sim, fundamental, do qual deriva a confiança e o reconhecimento do indivíduo como pertencente ao grupo, não apenas como um "integrante formal", mas sobretudo porque ele segue esse princípio moral que é prescrito. Para isto, não é determinante ser de origem kaiowa, mas sim a adscrição a esse circuito de obrigações e de reciprocidade.

Aqui, resta considerar a relação que se estabelece com o patrão. Um sinal do modo como isto se deu está no uso do termo karai exatamente para denominá-los. A referência a uma pessoa kaiowa prestigiosa (como são todos os idosos) se faz colocando-se esta palavra antes de se pronunciar seu nome. Vê-se, pois, uma extensão dela para definir este ser não kaiowa, indicando uma atitude de respeito a ele devotada.

\section{A relação com o patrão: sobre reciprocidade e compadrio}

Se os relatos hoje jocosos das pessoas revelam que nos inícios elas se escondiam no mato quando da aproximação de um karai, várias delas que hoje têm 70, 80 anos e que viviam em fazendas incidentes em seus locais de origem foram apadrinhadas pelos patrões de suas famílias. Pelas narrativas, disto decorreu, quase em regra, que as crianças com idade a partir de 6, 7 anos acabavam por realizar serviços para os patrões. Uma decorrência visível é que os pais dessas crianças (e, portanto, toda a família) ficaram mais fortemente atrelados a tais patrões. Alguns exemplos empíricos podem melhor ilustrar este quadro. 
Dona Ângela teve três filhos, vivendo em fazendas diversas no tekoha guasu chamado Lima Campo (nos municípios de Dourados e de Laguna). Ainda pequenos, os três se tornaram afilhados dos donos dessas fazendas. Nesses locais, se instruíram em algumas atividades: a filha, cuidando de uma casa de branco, e os filhos, montando a cavalo, laçando boi e tirando leite de vacas. O caçula de Ângela, Raul, casou-se e teve cinco filhos, todos tendo seus respectivos padrinhos, donos das fazendas onde os pais foram se instalando ao longo do tempo. Na fazenda onde eu o encontrei, em 2004, seu espaço residencial não diferia do ordenamento encontrado nas aldeias. Com isto se entende a habitação que tem o pátio (oka), espaço externo, como o locus principal da sociabilidade do grupo. Foi construída de modo a ter à sua volta a vegetação ainda existente e próxima a um córrego - onde eventualmente apareciam capivaras e onde Raul pescava. Esta residência guardava distância da casa do patrão.

Vale aqui observar que este afastamento espacial em relação à casa do patrão, eu pude constatar ainda em outro momento: em 2005, acompanhando uma senhora que, saindo de uma aldeia, foi à casa dos pais do marido. Chegando ao local, dentro de uma fazenda e de onde não se avistava a sede, encontramos um espaço cercado com mais ou menos $20 \mathrm{~m}^{2}$. Ao centro, estava a casa dos sogros.

Se, como dito, tanto quanto possível é guardado um distanciamento entre as residências de te'yi distintos, depreende-se daqui um modo de posicionar-se no território que se busca manter onde quer que as famílias se assentem. No caso das fazendas, o afastamento da sede indica um resguardo em relação ao patrão. Isto, percebe-se, não se choca com a intimidade que o trabalho dentro da sede estabelece, tanto para o patrão e sua família quanto para os te'yi, mas marca espaços e momentos distintos de vivência para ambas as partes.

Neste caso de Raul, o então patrão era padrinho de sua filha caçula. Dada a possibilidade de ele e a esposa Emiliana serem mandados embora da fazenda por qualquer fato que desagradasse ao patrão, foi possível perceber que tomar os patrões como compadres era uma estratégia para o casal se manter mais firmemente ligado aos patrões, visando aumentar a chance de permanecer na propriedade. Emiliana fazia visitas esporádicas às madrinhas dos filhos, delas recebendo roupas que serviam para o casal e para as crianças. Importa ainda (e sobremaneira) observar que o casal se mobilizou para conseguir que a mãe (e o então marido) e um irmão (casado) de Emiliana se instalassem em duas fazendas vizinhas àquela em que eles próprios se encontravam. Reconstituíram, assim, um grupo macrofamiliar, cujos membros, como observei, cooperavam entre si cotidianamente. 
Em fins de 2010, em encontro casual com um ex-cunhado de Raul, eu soube que este havia saído da fazenda, instalando-se em outra.

Originários respectivamente dos tekoha Jukeri e Mbarakay (situados no extremo sul do estado), o casal Dércio e Angelina vivia em fazendas distintas quando se conheceram e se casaram, por intercurso de uma irmã de Dércio. Após certo tempo, transferiram-se para uma das reservas criadas pelo SPI (a de Sassoró), para onde também fora a irmã de Dércio, e onde nasceram seus dois primeiros filhos. Da reserva o casal saiu para uma fazenda, onde permaneceu por mais de trinta anos trabalhando para o patrão. Seus cinco demais filhos nasceram justamente nesta fazenda, sendo que os do sexo masculino "se formaram" (termo que se refere ao crescimento de alguém) ali, aprendendo as habilidades necessárias para serem peões. Já a filha, a mais velha, aprendeu a se empenhar nos cuidados da casa-sede da fazenda. Nos anos 1980, a passagem de um padre pela fazenda determinou que os empregados não casados deveriam remediar esta situação. O mesmo se deu em relação ao batismo das crianças. Os filhos mais velhos do casal foram batizados pelos patrões. A que nasceu depois foi apadrinhada por um dos peões não índios, juntamente com a esposa. ${ }^{14}$

Quando encontrei este casal, ele havia sido dispensado pelos filhos do patrão, e estava instalado em um terreno na periferia da cidade de Iguatemi, de propriedade destes mesmos filhos. O discurso era de que este espaço (apenas cedido) era uma compensação pelos anos trabalhados na fazenda. Ali estavam a filha caçula e um filho (com esposa e filhos) vivendo com Dércio e Angelina. A filha mais velha, casada e com filhos, morava numa casa a uns 100 metros de distância, visitando cotidianamente os pais, e outro filho se instalara na reserva de Sassoró, com a esposa. Os que estavam em Iguatemi, com exceção dos mais idosos, circulavam com frequência entre a reserva de Sassoró e uma fazenda onde se encontrava um último filho do casal. Dércio quase não visitava a irmã antes referida e o cunhado, que desde o início dos anos 1990 viviam numa Terra Indígena (Jaguapiré). Ele, porém, recebia a visita de filhos e de netos desta irmã. Tal circulação nesses espaços (relativamente próximos entre si) possibilitava a manutenção dos elos também neste grupo macrofamiliar.

Um terceiro exemplo envolve pessoas do tekoha Ñanderu Marangatu e um dos seus patrões, que apadrinhara várias crianças das famílias que viviam em sua fazenda instalada naquele tekoha. Ele destacava o fato de ser um pioneiro no lugar. Ocorre que em 2000, em uma conversa no auge do conflito pela recuperação do tekoha, fez um desabafo em tom de mágoa e indignação. Disse que dedicara toda a vida a tornar aquela terra produtiva, e os índios se rebelavam contra ele. Isto lhe era mais pungente porque dois 
dos que se destacavam ele havia apadrinhado e acompanhado o crescimento. Já feita a reocupação do tekoha, no acampamento montado (justamente dentro dos limites da fazenda), unindo dois grupos macrofamiliares de quatro gerações e que conformavam uma única comunidade política, na visão destes dois afilhados, tal relação de apadrinhamento não tinha a menor relevância. Destacava-se, sim, a acusação de que, quando se estabelecera no lugar, o fazendeiro queimara casas de seus parentes, expulsando-os. A percepção - compreendo hoje - era de um ultraje ocorrido, que resultou numa vida degradante por muitos anos para toda aquela gente e seus familiares. Tratava-se, então, da recuperação de uma dignidade de condição de viver.

Sem multiplicar inutilmente os exemplos, passo a dialogar com uma bibliografia sobre patronagem e compadrio. Assim, debruçando-se sobre o contexto de São Paulo seiscentista, Monteiro (1994) sustenta que o compadrio foi "um passo significativo para a integração dos índios à sociedade paulista" (:163). Tomando registros de batismo, que denotavam um padrão hierarquizado (entre padrinhos brancos, índios e escravos), sua percepção é de que isto revelaria estratégias de socialização (:162). A partir de minha análise de campo, veremos em que direção os dados nos conduzem.

De início, remeto-me às colocações de Arantes (2011) - desenvolvidas no "sertão da Bahia" ainda nos anos 1960 e referência para o contexto brasileiro. Ele diz que observou uma informalidade no estabelecimento do compadrio, nem sempre se efetivando o ritual católico do batismo. Mas centro-me especificamente em dois pontos do seu trabalho. No primeiro, em sua perspectiva de análise estrutural, o autor não deixa claro o peso que dá à diferenciação que Ravicz fez entre padrinazgo — que diz respeito apenas à relação padrinho/afilhado - e compadrazgo — referente à relação pais/padrinho (cf. Ravicz apud Arantes 2011:97). O outro ponto concerne à componente moral que ele reputa ao compadrio. Sobre isto me deterei logo abaixo, mas no primeiro caso fica a impressão de que ele toma como relevante a distinção envolvendo pares de pessoas estruturalmente posicionadas (pais/ filhos, padrinho/afilhado, pais/compadre). Porém, para o foco nos Kaiowa, incorrer numa tal distinção não ajudaria a compreender a relação entre o patrão e todo o grupo doméstico indígena, mas sim fragmentaria algo cuja dimensão, pelo que se vislumbra, só é entendida em sua inteireza.

Assim, vale considerar o trabalho de Stolcke (1982) sobre o colonato, desenvolvido da segunda metade do séc. XIX até meados de 1950 em São Paulo. Embora sem referências ao compadrio, a autora enfatiza que foi importante a rentabilidade da família para a reprodução barata da força de trabalho e observa que "a vantagem da ameia sobre o assalariamento derivou em parte de uma ideologia de família preexistente, partilhada por 
ambos, fazendeiros e trabalhadores e que pressupunha a combinação de esforços e auxílio mútuo entre os membros de uma família para benefício dela como um todo" (:47). Ela ressalta que enquanto houve a convivência do colonato com o sistema escravista, os colonos plantavam e cuidavam de um número determinado de pés de café, enquanto "todas as demais tarefas continuavam a ser executadas pelos escravos" (:44). Ora, como dito antes, todo o trabalho para a efetiva instalação, o desenvolvimento e a manutenção das fazendas em questão foi realizado pelos indígenas, em sua configuração familiar. Ademais, estes tinham as tarefas para a manutenção dos próprios lares e vidas.

Desta forma, a percepção da autora sobre "uma ideologia de família preexistente" para benefício do próprio grupo é aqui pertinente. Observando ser o grupo doméstico um imperativo para os Kaiowa, cuja manutenção é um valor, entende-se o quanto isto serviu aos interesses dos fazendeiros. Mas cabe notar que, se para os patrões era importante a mão de obra, para os indígenas a relação não seria menos relevante no que tange a interesses que nela incutiam. Ressalte-se que, por uma longa experiência, os indígenas puderam formular uma compreensão sobre o conteúdo e os corolários desta relação para os brancos. Decorre daí que pode não só ser importante (na medida em que é útil) "ter patrão", de modo que isto se torna uma estratégia a ser entabulada, mas também coloca-se em questão o julgamento de uma boa performance. Como Barth (2000a) alertava para o fato de que as pessoas pretendem ter suas performances julgadas pelos parâmetros de seu próprio grupo, tem-se uma compreensão sobre um comportamento valorizado pelo patrão e, consequentemente, um comportar-se segundo esse parâmetro. Trata-se, pois, de uma performance que é política, ${ }^{15}$ na qual se dá demonstrações de lealdade e de destreza no trabalho, obtendo como resultado a possibilidade de poder contar com o patrão e assim obter benefícios.

Retornando a Arantes, temos o seguinte:

Do meu ponto de vista, a especificidade das relações de compadrio só pode ser determinada quando se as considera como um tipo de contrato moral entre adultos, que pode ser entendido (1) em termos do significado religioso dos rituais que o estabelecem, (2) os status prévios das pessoas envolvidas conforme determinados pelas regras costumeiras para se escolherem compadres (levando em conta o sistema de parentesco, a estrutura social e os valores que os camponeses lhes agregam) e (3) as expectativas recíprocas envolvidas (2011:77, grifo meu).

Tal afirmação remete a um diálogo com autores de uma literatura já clássica. Mintz e Wolf (1968) afirmaram o caráter da vontade recíproca e 
um efeito de interdependência - mesmos aspectos encontrados em Pitt-Rivers (1976). Mas reportando-se à relação entre padrinho e pais da criança (i.e., entre compadres), este último autor destaca que, numa relação entre empregador e empregado, a suposta igualdade de estima, que geraria uma igualdade moral, é o que contrabalançaria a desigualdade social entre as partes (:322). E diz ainda:

A reciprocidade não é, então, uma questão de cálculo material, mas de coração, uma questão de confiança mútua: cada um deve estar ao serviço do outro, pronto para ajudar quando necessário no que quer que seja requerido. Tal reciprocidade leva ela própria à exploração, especialmente quando os participantes não são de fato iguais, conforme os exemplos de seu uso entre o proprietário e seus peões nas haciendas da América Latina mostram (:323).

Desta argumentação, focada sobre o aspecto emocional-afetivo, se pode perceber por que o compadrio foi também definido como uma forma de parentesco - o "parentesco ritual" (como define o próprio Pitt-Rivers neste trabalho), ou o "coparentesco ritual" (como o denominaram Mintz e Wolf no texto acima). E eis um elemento que pode ser chave em meu propósito aqui. Em vez de partir para uma análise quantitativa da emoção que os indivíduos trariam em suas relações, atentemos à concepção do mesmo Pitt-Rivers, a do necessário consentimento mútuo para se estabelecerem confiança e boa vontade, possibilitando a relação. Assim, a natureza desta (relação) tem muito do que na literatura é posto em termos de assistência (e/ou proteção).$^{16}$

Mas como se colocariam esses aspectos na relação entre os indígenas em causa e seus compadres/"patrões"? A rigor, só podemos responder a isto atendo-nos à complexidade resultante de muitas nuances que revestem os interesses e os significados investidos de parte a parte no estabelecimento da relação. Devem ser vistos concretamente os casos em suas singularidades, verificando-se as motivações e as circunstâncias que impulsionam as pessoas a agir. Mas se isto é correto, é igualmente correto que o comportamento não se define de modo aleatório, havendo, ao contrário, parâmetros a lhe colocarem constrangimentos, sendo os de ordem moral muito importantes; de fato, foi o que pudemos acompanhar em termos dos valores implicados no seio do te'yi.

Aqui, as reflexões de Bailey (1971) nos são profícuas; como Arantes, ele se centra no aspecto moral das relações. De fato, tomando como eixo as noções de "reputação" e de "comunidade moral", ele se refere a "estratégias de gerenciamento da reputação" — que se baseiam em opiniões de outras pessoas sobre o sujeito (ego). Sua definição para "comunidade moral", que 
viabilizaria a construção de uma reputação, é: “[...] para se referir àqueles que são aptos (prepared) a fazer julgamentos morais sobre um outro. O homem imoral não é menos parte de sua comunidade do que o é o homem moral (isto é, bom), pois ele é julgado pelos mesmos padrões morais [...]" (:7, grifo meu).

Daqui se infere que deve haver um compartilhamento dos valores morais - caso contrário, não se faz parte da mesma comunidade. É exatamente o que sobressai da sua ressalva, ao afirmar que as pessoas que estão fora da comunidade moral têm diferentes tipos de reputação. Mas Bailey claramente parte de uma homogeneidade existente entre os membros de uma comunidade. Dando uma definição mais precisa, ele diz:

Eles compartilham a mesma perspectiva de vida; querem os mesmos tipos de coisas; têm os mesmos modos de "nomear" (wording) o mundo; compartilham um alusivo, lacônico e econômico sistema de sinalização e concebem-se a si mesmos como uma entidade, regida por leis e regularidades e padrões de moralidade, e posicionada contra um mundo externo imoral (:14).

Numa direção muito similar temos a análise de Campbell. Considerando os pastores na Grécia, ele partiu de uma situação em que a assimetria entre as pessoas não era tão acentuada. Ao focar sobre o papel do presidente do povoado e seu poder sobre os direitos de pastagem, ele diz: “Em seus esforços para chegar a um acordo sobre sua autoridade e influência, os Sarakatsanos tentam atraí-lo para uma forma de relação pessoal que introduzirá um elemento moral de mútua consideração" (Campbell 1977:252).

Assim, Campbell podia ver como plausível um "elemento moral de mútua consideração" que seria determinante do compadrio em causa. Ora, pelo que vimos até aqui, a conformação de uma comunidade moral implica a necessidade de partilhar e de seguir certos códigos. Imaginar que uma clivagem étnica feita a priori seja uma necessidade inexorável não é um dado empírico, mas uma pressuposição (equivocada) do analista. O nó da questão, de fato, está em que não se trata tanto de uma questão de etnicidade, mas sim de assimetria social, ou de hierarquia. Na relação com o patrão, a hierarquia é um aspecto essencial, que a fundamenta. Desta forma, é imperativo discutir essas bases, de modo que me remeto à questão da dominação, investigando principalmente o modo como ela se manifestaria no caso analisado.

Antes de apelar para a ideia weberiana de uma dominação com probabilidade de ser aceita por ser considerada legítima (Weber 1982), as reflexões de Scott $(1985,1990)$ parecem se coadunar melhor com o que pude depreender em campo. ${ }^{17}$ Este autor toma como ponto de partida as relações 
de subordinação, as quais acabam por compreender "um comportamento arbitrário e caprichoso" de parte do dominante, havendo invariavelmente um elemento de terror pessoal (personal terror) permeando essas relações. Conforme diz, as formas deste terror são, por exemplo, espancamentos arbitrários, insultos e humilhação pública, estando os dominados em perene submissão ou ao menos sob a ameaça desse terror, quando não da sua concretização (Scott 1990:xi).

Como a ilustrar tais observações de Scott há relatos dos senhores Arcênio Almeida e Arturo Fernandes, originários do tekoha Karaguatay. Em entrevista (em 11/10/2010), o primeiro disse que os encontros com o fazendeiro Adão, que os expulsou justamente de Karaguatay, eram ditados por ameaças:

Naquele período, não deixavam chegar visitantes na casa do Arturo; impedia mesmo, com arma de fogo na mão. Uma vez, o Adão nos barrou com revólver na mão, falou: "Tem que voltar rápido", falou Adão. "Na casa do Arturo vocês índios não chegam. [...] Aqui eu que mando, com essa aqui", mostrou revólver na mão.

E Arturo:

Em casa, os meus filhos brincavam com tambor, fazendo barulho, por isso o Adão foi me avisar pra não fazer barulho. [...] No outro dia chegou com trator. Adão ficou bravo e falou que tinha que sair do lugar. Aí pegaram a minha mudança e carregaram no trator, tudo muito rápido. Assim me levaram e jogaram na entrada em frente à aldeia Jaguapiré, em 1994.

Assim, tomemos dois pontos da reflexão de Scott. O primeiro se refere à ideia de "resistência", que ele aplica às estratégias dos dominados; o segundo é a proposição de que estes últimos, em geral, não contestam abertamente sua subordinação (1985:29) — vindo a realizar o que ele denomina de infrapolítica. A noção de resistência pode ter diversos sentidos, mas certamente aquela que implicaria tão somente um esforço de contraposição é inadequada ou insuficiente para explicar as ações e as condutas dos sujeitos kaiowa em relação aos patrões, pois estas, na maior parte das vezes, envolvem intenções de negociação e arranjos. Assim, até mesmo em consequência disto, de modo geral, as suas contrariedades não são efetivamente manifestadas de modo aberto. A ilustração talvez mais evidente disto pode ser encontrada na expressão nativa ñembo tavy, que significa falar como um tolo, idiota (isto é, tavy). Neste caso, sua base está em não expressar qualquer discordância com o interlocutor. Procura-se, deste modo, evitar choques frontais e retaliações. 
Mas falta considerar um fator de cunho histórico fundamental: por um lado, o processo de expropriação da terra, com a consequente territorialização nas reservas do SPI (referida no início), e por outro, a reação dos indígenas a esse processo - a partir de fins dos anos 1970 e que perdura até hoje. Nisto tem sido fundamental o papel das Aty Guasu ("Grande Assembleia [dos Kaiowa e dos Ñandéva]") que, ao longo de mais de três décadas, constituíram-se em um espaço de compartilhamento de experiências de expropriação da terra e de constante reflexão sobre elas, resultando no delinear de estratégias para a reocupação dos espaços (os tekoha) expropriados. ${ }^{18}$ Sobre as Aty Guasu tornarei adiante, mas importa destacar que, neste proceder, famílias kaiowa e ñandéva vêm sendo retaliadas com grande violência pelos fazendeiros. ${ }^{19}$ A instauração deste embate criou um pano de fundo novo - uma nova situação histórica, diria Oliveira $(1988)^{20}$ — para as relações entre indígenas e não indígenas na região.

Podemos ver até aqui que a questão não é ser ou não ser leal ao patrão, mas até que ponto se submeter a ele. Se se reivindica terra, em jogo está a (im)possibilidade de permanência nela. Se não se reivindica, estão em causa os benefícios de se "ter patrão", conforme indicado antes. Caso não haja ameaças à manutenção da relação de interdependência, eventuais desentendimentos entre os "clientes" indígenas e seus patrões terão um caráter restrito, configurando-se apenas como uma insatisfação momentânea, ou a saída à procura de outro patrão que proporcione similaridade (ou melhoria) de condições. Mas se se apresentar um conflito acirrado, com uma articulação para reivindicar terra, essa relação facilmente se desmancha. Em suma, para as famílias reivindicantes deu-se uma alteração nessas relações, com efeitos que se projetam para a população indígena como um todo. Mas para algumas outras essas relações têm se mantido, isto é, para aquelas que (em número muito reduzido) ainda vivem em fazendas, ou as que realizam trabalhos pontuais (changa) para fazendeiros (como, por exemplo, conserto de cercas e trabalho durante a colheita em pequenas fazendas).

\section{Conformações identitárias}

Neste ponto busco uma síntese dos dados e dos argumentos apresentados para correlacionar a relação dos Kaiowa com o patrão e os processos identitários daí decorrentes. Retomando a epígrafe inicial, temos Barth que reflete sobre (não) se ter uma cultura separada. Para ele, o material cultural, ao se encontrar em fluxo, é apropriado de modos particulares, havendo sínteses distintas dele. De fato, tanto Hannerz (1992) quanto o próprio Barth (1993 
e 2005) já destacavam bem: uma coisa é a cultura, outra é a organização social, sendo que, a partir desta última, é feita a organização dos materiais culturais - para Barth, através dos "tipos organizacionais", dos quais o grupo étnico é um exemplo (Barth 2000a).

Mas o ponto que quero focar é: se, como vimos, é certo que não se pode compreender a vida dos Kaiowa sem considerar a relação com não indígenas, também é certo que essa relação não precisa englobar a totalidade da vida de ambos. São necessários apenas alguns elementos para criar convergência, que pode ser momentânea ou perdurar ao longo do tempo. É então pertinente a afirmação de Barth (2000a) de que a interação entre grupos étnicos pode ocorrer em alguns setores de atividades, enquanto outros são preservados. No caso das relações com o patrão, vê-se que a interação se efetua no âmbito das atividades que são de interesse deste último; os demais aspectos da vida dos indígenas ficam, assim, à parte. Configuram-se, portanto, instâncias múltiplas e distintas de interações, pautadas por valores, interesses, intenções também distintas, em diferentes espaços de socialização e sociabilidade.

Aqui, algumas observações de Eriksen (2010) são de auxílio. Nas ilhas Maurício, ele constatou que os ilhéus hindus e creoles "geralmente se encontravam sem referência implícita ou explicita às suas respectivas identidades étnicas, por exemplo, quando a situação é definida por seus status como colegas ou parceiros de negócios" (:37). E complementa:

Em muitas outras situações, essa particular identidade não é ativada; isso não parece relevante na definição das situações sociais. Em outras palavras, os indivíduos podem ter diversos status e diversas identidades possíveis e é uma questão empírica quando e como as identidades étnicas se tornam aquelas mais relevantes.

Assim, o autor aponta que a identidade propriamente étnica é em muitas situações subvalorizada, isto é, fica em um plano secundário. Na região aqui em causa, conforme vemos, a diversidade étnica se configura como um pano de fundo para as relações. Utilizando os termos de Barth (2000a), a identidade étnica é imperativa, impregnando vários aspectos da vida das pessoas. Mas neste nosso caso necessitaríamos verificar em detalhes tal afirmação. Como observado, uma disputa iniciou-se com a ocupação da terra pelos não indígenas, com a consequente expropriação dos indígenas. Um discurso generalizado entre os fazendeiros é que eles sempre viveram em paz com os índios, sem haver qualquer conflito. Mas isto não corresponde à realidade. Em documentos do SPI dos anos 1940 são encontradas reiteradas queixas de indígenas contra a expulsão (ou ameaça de) de suas terras por 
fazendeiros (v. Barbosa da Silva 2013). O problema, dizem estes últimos, está nessa espécie de rebelião dos índios — sempre imputada a forças externas, via ONGs nacionais e estrangeiras (e mesmo a antropólogos). Por um lado, esses proprietários rurais não reconhecem a expropriação impingida aos indígenas e, por outro, a proteção que acreditam ter dado a eles ao longo do tempo (as dádivas feitas) aparece como um valor, de modo que o seu não reconhecimento pelos indígenas é tido como uma falta moral grave.

Ora, numa relação com alto grau de assimetria, como é típico das situações coloniais (Balandier 1951) e, portanto, de um sistema de dominação, uma compreensão em termos de dádiva é justamente o que possibilita a dissimulação da assimetria, e é sempre o que leva a borrar, no cotidiano (duradouro), a desigualdade. A "mentira" da dádiva não está, como propôs Mauss (1993b), num pretenso desinteresse das pessoas pela coisa posta num circuito; está, sim, na pretensão (e não mais que pretensão) de mascarar uma desigualdade de condições dadas, já de início, na troca. A "boa vontade mútua", necessária à relação de patronagem, existe certamente; mas os processos sócio-históricos, numa trama de dominação, também se fazem presentes e, portanto, devem ser levados em conta.

É evidente que na ausência de conflito aberto (ou acirrado), e em que pesem também aspectos de personalidade dos patrões, bem como maior ou menor frequência em termos de relações de dar-receber-retribuir, há avaliações diversas sobre cada patrão, como aquele que "ajuda mais" (ou menos). Ademais, como são relações estabelecidas com grupos familiares específicos, a dimensão étnica, no sentido de pertencimento a um povo, não necessariamente se coloca e é determinante. O que temos aqui são jogos de escalas distintas nas relações: um no nível familiar e outro no nível étnico. Assim, a percepção da ausência de conflitos pode ganhar aspecto de verdade. Porém, há aqui dois fatores a considerar: 1. dois sujeitos distintos (o patrão e o indígena) ocupando um mesmo espaço territorial, portanto, disputando-o em condições desiguais; 2. no dia a dia, a dominação subordina e tem o poder de calar vontades outras. Nestes termos, a não existência de conflito, como é vista pelo patrão, é efeito desta possibilidade sua de sobrepor (e assim impor) sua vontade às demais. Enquanto foi permitido às famílias permanecerem em suas terras, não se colocava uma situação de conflito.

Ao se considerarem as relações delineadas com "não indígenas pobres" e com "não indígenas patrões", cabe retomar as noções de "comunidade moral" de Bailey (gerada por uma moralidade compartilhada), e de "comunidade cultural" de Barth (como vimos no início, gerada por uma congruência de códigos e valores). Entrevimos a possibilidade de que, ao se inserirem num te'yi, os primeiros venham a compor ambas as comunidades. Mas em 
relação ao patrão, a possibilidade de se gerar uma comunidade se daria, penso, nos termos de uma "comunidade de cooperação", que é definida por Gluckman (1987 [1940]) como aquela constituída a partir da existência de interesses e objetivos em comum. Se esta definição é válida também para o primeiro caso, neste último ela se conformaria a partir de parcos elementos. Assim sendo, vemos que em um plano abstrato apresenta-se uma moralidade kaiowa, pensada como de um grupo (étnico) homogêneo; tal moralidade é contraposta a uma moralidade dos karai, vistos também como grupo homogêneo. Na prática, as coisas funcionam de modo mais complexo.

Outros elementos deste quadro podem ser vislumbrados no conjunto de ações que constituem a reocupação de um território que foi expropriado. Tal complexo tem várias etapas, de modo que pode ser pensado como um evento. ${ }^{21}$ Seu início se dá com a decisão de um grupo de reocupar a terra. Daí, torna-se necessária a avaliação do momento propício, que ocorre após vários dias de realização de jeroky — ritual constituído por cantos e danças de comunicação com os deuses, coordenados por um xamã (ñanderu) de reconhecida competência, que é secundado por seu(s) auxiliar(es), os yvyraija. Na verdade, trata-se não de um momento definido pelas divindades, com as pessoas (incluindo o ñanderu) tendo um papel passivo em receber a informação, mas antes da construção desse momento propício, em que todos participam em diálogo com essas divindades que, como dito antes, são também elas parentes. Assim, são detectados e neutralizados possíveis seres e substâncias maléficos e pedida proteção às divindades. Para mais eficácia, todos (homens, mulheres e crianças) que se reconhecem como pertencentes àquele espaço territorial devem participar.

Decidido o momento, faz-se a reocupação (que é também uma retomada, no sentido político do termo): as pessoas entram no local escolhido e constroem barracos onde residirão. Ali, os jeroky continuam para manter a proteção, e "as autoridades" não indígenas são avisadas do ato realizado. Em regra, quando a reocupação vem a ocorrer, diversos documentos manuscritos já foram enviados pelos indígenas a essas mesmas autoridades, apresentando a demanda pelo território e solicitando a sua demarcação. A expectativa do grupo é conseguir permanecer no lugar, ali desenvolvendo a vida. Caso ocorra expulsão, nova(s) tentativa(s) de reocupação será(ão) feita(s).

Com este evento nos reencontramos com as proposições que Weber (1983) já estabelecera; o fundamento político acaba tendo um papel extremamente relevante, o que ele denominou de "comunização" — deixando-nos, com este termo, vislumbrar um sentido de produção de aproximação, de coesão, enfim, de criação de um grupo, precisamente. Indo nesta direção, como já notáramos, na situação de retomada 
[...] constitui-se justamente o que Max Weber [...] observou como crucial para um processo de criação de uma comunidade como grupo efetivo, ou seja, uma memória de lutas (podendo-se daí inferirmos o compartilhamento de sofrimentos e adversidades) que, segundo ele, muitas vezes tem mais força do que um laço de caráter apenas cultural ou unicamente de sangue (Barbosa da Silva 2013:76).

É certo que antes mesmo de o ato de reocupação acontecer, esse grupo existia, pela experiência comum tanto de pertencer ao tekoha quanto de ter sido dele expulso. O retorno a terra, contudo, permite que ele se rearticule, sendo reforçado o caráter emocional desse pertencimento, com as pessoas tendo a percepção mais vívida da conformação do seu grupo. É a reocupação/ retomada que, por fim, reaviva a memória de luta (desde a expulsão, mas também adensando-a, ao atualizá-la) a que Weber se referiu.

O retorno ao tekoha é pensado ainda como a retomada de uma comunhão que abrange todos os parentes, em sua generalidade, incluindo as divindades e as almas/pessoas dos parentes falecidos que permanecem ligados ao tekoha. ${ }^{22}$ Mas em termos dessa "comunização" é necessário precisar alguns pontos. A comunidade (política neste caso) é formada por famílias extensas de pelo menos três, mas geralmente de quatro gerações (dependendo do seu crescimento no tempo, assim como das condições de compactação das pessoas expulsas da terra e depois dispersas no espaço) que pertencem ao tekoha em causa. Pode ocorrer que uma das famílias se apresente como mais forte, política e numericamente falando, portanto, terá seus integrantes à frente da demanda pela terra, liderando e conduzindo a reocupação. Assim, outra(s) família(s), sempre extensa(s), acaba(m) por orbitar no seu entorno - em geral ocorrendo matrimônios entre elas, com os integrantes desta(s) última(s) sendo exportados para a primeira. ${ }^{23}$ Neste caso, temos uma única comunidade política operante. Já na situação de não haver grandes dissimetrias entre as famílias, estas se mantêm como adversárias, disputando o controle político do território. Teremos então, certamente, comunidades políticas diversas. De qualquer modo, neste evento é reforçado um "nós" (kaiowa), definido em relação a um "eles" (os opositores, não indígenas).

Outro elemento a ser considerado é a já referida realização das Aty Guasu. Sendo "aty" traduzível por "reunião" e "guasu" significando "grande", tem-se: "[as] Grandes Assembleias [dos Kaiowa e dos Ñandéva]". Elas tiveram início em fins dos anos 1970, com o suporte logístico do Projeto Kaiowa e Ñandéva (PKÑ) $)^{24}$ e do Conselho Indigenista Missionário (CIMI), coincidindo com a expulsão em massa dos indígenas de seus tekoha. Tornaram-se um espaço crucial de compartilhamento e de reflexão sobre as experiências de expulsões e de retomadas (incluindo a divisão da dor e das 
emoções), possibilitando um formidável lócus de comunização e de produção de sínteses culturais. Ao reunirem famílias de todo o cone sul, elas têm permitido a produção de aproximações que perpassam o âmbito restrito de cada comunidade (política), tornando essas aproximações propriamente étnicas.

Em contrapartida, num estado marcado pelo "agronegócio", assiste-se a um movimento dos fazendeiros para se autoapoiarem (sendo importantes os sindicatos rurais locais ${ }^{25}$ ), ao mesmo tempo em que produzem um discurso (veiculado pela mídia local) para a cooptação de pequenos proprietários e não índios em geral, argumentando-se que os índios querem expulsar todos. A demora do Estado em regularizar os territórios indígenas tem como efeito a proliferação de reocupações, de modo que este discurso acaba tendo algum efeito. Assim, vê-se que o conflito vem a ser configurado propriamente como étnico por ambas as partes - com base no contraste e na contraposição (v. Cardoso de Oliveira 1976).

\section{Considerações conclusivas}

A partir do quadro geral delineado, é importante, de imediato, recuperar alguns aspectos que aportam uma complexificação sobre a relação social que é a patronagem. Tendo em vista a literatura a respeito, um primeiro deles se refere ao discurso sobre a coesão que esta relação produziria entre seus partícipes, com uma lealdade mútua, de base afetiva. O que se evidenciou de modo mais contundente foi que a adscrição ao grupo doméstico (te'yi) e às suas obrigações não tem para os Kaiowa a mesma carga emocional-afetiva e moral que tem a adscrição à relação com o patrão. A lealdade empenhada em cada caso, nota-se, é de natureza muito diversa, com lógicas de reciprocidade também diversas, revelando-se, ao fim, a preponderância da primeira. Ademais, observe-se que, não obstante a subordinação que está na base, a patronagem contribui para a provisão do próprio grupo doméstico indígena e a manutenção das obrigações de reciprocidade que lhe dão suporte e vida. Neste quadro, o julgamento moral do patrão sobre um comportamento do indivíduo pode não ser (e em geral não é) o mesmo que é feito pelo próprio indivíduo e por seus pares no seio do seu grupo familiar. É isto que o escancarar dos conflitos pela terra veio a patentear.

Já outro aspecto concerne aos elementos de base para a construção do étnico - sem esquecer aqui o papel do fator tempo, no sentido das configurações temporais desenhadas propriamente como situações históricas (Oliveira 1988).

Assim, um eixo fundamental, constata-se, foi dado pelo parentesco como forma de organização das relações. Como vimos, a constituição da comunidade 
de parentesco (a hente kuera), uma forma de adscrição primordial, pode ocorrer com a incorporação de um não índio. O que passa a se revelar então como importante é, primeiro, a base propriamente moral desta comunidade de parentes e, segundo, que a formação e a manutenção da comunidade moral são determinantes na vida cotidiana deste grupo de parentes. Como consequência, ela tem, com o decurso do tempo, mais probabilidade de se sedimentar do que o étnico em si e por si só. Em tal dinâmica, seguindo o que foi argumentado, a própria construção da moralidade se realiza por meio do compartilhamento de experiências, investimentos e expectativas em comum, isto é, de um vivido em comum. Mas sustento, sobretudo, que é preciso uma avaliação deste vivido enquanto base de construção de um futuro em comum. Partindo-se sempre do parentesco, a forma mais acabada disto seria a produção de pessoas que fossem vistas como herdeiras de um patrimônio comum.

É aí que uma possível adscrição de karai no grupo de parentes encontra uma bifurcação fundamental, sendo este um patrão ou não. Em outras palavras, a questão em tela é: qual comunidade moral poderia adscrever os filhos de Tupãsy Ka'acupe e San José (como no mito narrado), enquanto herdeiros comuns destas duas figuras, num mesmo e único percurso de vida?

Cabe lembrar que o processo histórico de expropriação das terras de ocupação tradicional (tekoha) desses indígenas estabeleceu uma relação fundada numa hierarquia e numa dominação. As formas iniciais de resistência para a convivência pacífica com o karai foi a de não contrariá-lo e buscar assim permanecer na terra. Já a dinâmica de reivindicação e, sobretudo, as reocupações dos tekoha geraram uma repressão cada vez mais violenta. Considerando-se, pois, a interdependência baseada na separação e na cooperação — como sugeriu Gluckman (1987 [1940]:243) — a atual situação histórica produz uma diminuição da margem de sua concretização. Ocorre, porém, que nada determina que ela não seja revertida com um quadro de regularização fundiária que permita uma nova adequação entre estes dois grupos - kaiowa e karai. De fato, no momento, a disputa pela terra aguçou uma diferenciação propriamente étnica, de modo que o caráter político dessa diferença passou para primeiro plano, como um cenário para as relações.

Weber (1983) já refletiu a respeito de tal dinâmica, sugerindo a comunidade étnica como decorrência de uma comunidade política. Neste caso em análise, tudo ocorre a partir de um processo histórico que ainda está em marcha.

Com isto dado, vê-se que um discurso de paz e harmonia que teria existido no passado entre os fazendeiros patrões e os indígenas traz em si todo um conjunto de implícitos. O que se fez aqui foi lançar luz sobre eles, revelando as suas condições de produção. 
Recebido em 05 de agosto de 2015

Aprovado em 04 de abril de 2016

Alexandra Barbosa da Silva é professora adjunta na Universidade Federal da Paraíba (UFPB). E-mail: <alexandrabar01@gmail.com>

\section{Notas}

* Uma versão incipiente deste texto foi apresentada na $27^{\text {a }}$ Reunião Brasileira de Antropologia, em 2010. A base inicial de sua formulação, por sua vez, esteve posta em minha tese de doutoramento (Barbosa da Silva 2007). Aproveito para externar meu agradecimento aos pareceristas deste trabalho.

${ }^{1}$ No entanto, Barnes reconhece que, mesmo numa "situação tribal-limite", em que "todo mundo conhece todo mundo", mesmo aí "os originadores de ação deveriam ser seletivos, posto que não poderiam mobilizar toda a sociedade todas as vezes que precisassem obter algo" (Barnes 1987:188).

${ }^{2}$ Com "adscrição" considero o pertencimento a um grupo e a sujeição aos elementos que o fundamentam.

${ }^{3}$ Para Oliveira, a territorialização é uma intervenção política que associa um território com limites precisos a um grupo.

${ }^{4}$ No Brasil, os grupos Kaiowa, os Ñandéva e os Mbya são de fala guarani; em Mato Grosso do Sul encontram-se apenas os dois primeiros.

${ }^{5}$ Sobre esta dupla atuação do SPI, ver Lima (1995).

${ }^{6} \mathrm{O}$ cerrado de MS inicialmente foi ocupado para a pecuária extensiva e, posteriormente, para a produção de algodão, arroz e milho, com a soja ganhando primazia devido ao mercado externo (v. Terra 2006). Em meu levantamento para identificação e delimitação de terras no extremo sul (Barbosa da Silva 2013), constatei expulsões das famílias a partir dos anos 1940, com a chegada do gado. No início dos anos 1980 foi feito desmatamento em Tacuru e Iguatemi. A progressiva cristalização destas atividades foi dispensando a mão de obra indígena.

${ }^{7}$ Literalmente, trata-se da transcrição para o guarani da palavra "gente", como pronunciada no castelhano da fronteira. 
${ }^{8}$ Por household ("grupo doméstico" ou "unidade doméstica") geralmente se entende um conjunto de indivíduos sob um único teto. Esta definição é limitada, sendo mais profícuo o proposto por Wilk, entre os Kekchi Maia do Belize: pensar a variabilidade de agregações possíveis a partir da cooperação realizada entre as unidades habitacionais que conformam este grupo (Wilk 1984, 1997). Vide também Mura (2006) e B. da Silva $(2007,2009)$.

${ }^{9}$ Esse mito se encontra em Melià et. al. (1976).

${ }^{10}$ Narrada pelo xamã Atanásio Teixeira e registrada numa versão mais ampla por Mura (2006).

${ }^{11}$ Susnik (1979-80) descreve relações de aliança entre os Guarani e os espanhóis através do cunhadismo, com a cessão de pessoas do sexo feminino.

${ }^{12}$ Esta dinâmica é válida para ambas as partes. Os indígenas conhecem bem as idiossincrasias de cada patrão, necessitando lidar com elas. Desenvolvem, portanto, maior poder de observação e de conhecimento, não operando apenas com estereótipos generalizantes. Já para os não índios, numa condição de superioridade social que construíram, os estereótipos que definem são mais operativos, funcionando para a reprodução da dominação. A respeito dos estereótipos e seus usos, ver Eriksen (2010).

${ }^{13}$ Conforme argumentado em outro espaço (Mura \& Barbosa da Silva 2012), a expressão teko laja kuera aponta para a possibilidade de engendramento de grupos diversos (étnicos), fazendo do grupo doméstico, em alguns casos, uma unidade sociológica fundamental para buscar compreender a conformação de padrões culturais.

${ }^{14}$ Estas relações, mais horizontais, são por vezes expressas pelos indígenas em termos de "amizade". Embora relevantes, não irei explorá-las aqui.

${ }^{15}$ Wolf falava da "pantomima ritual de dependência" (2003a:171).

${ }^{16}$ Importa considerar que essa literatura às vezes apresenta, de modo propositalmente indistinto, a díade patrono-cliente como intercambiável com aquela de patrão-cliente, partindo-se da ênfase na ideia de proteção - que justifica sua relação com a ideia de santo protetor (o "patrono"), presente no catolicismo praticado entre camadas ditas populares.

${ }^{17}$ Minhas próprias constatações convergem para o apontado por Wolf: "a ratificação do poder sempre cria fricção" (Wolf 2003b:333).

${ }^{18} \mathrm{Tal}$ ação resultou na identificação e demarcação de mais de 20 terras indígenas, as quais não correspondem às necessidades dos cerca de 50.000 indivíduos kaiowa e ñandéva em Mato Grosso do Sul.

${ }^{19}$ Os relatos indígenas e os registros do MPF indicam tiroteios perpetrados por seguranças particulares, expulsões com espancamentos e ferimentos por armas de fogo, desaparecimento e assassinato de indígenas. 
${ }^{20}$ Esta "não se refere a eventos isolados, mas a modelos ou esquemas de distribuição de poder entre diversos atores sociais" (Oliveira 1988:57, grifo no original).

${ }^{21}$ Conforme sugerido por Barth (1993:173), como produto dos atos dos sujeitos.

${ }^{22}$ Sobre isto, vide Benites (2014).

${ }^{23}$ Essa dinâmica de conformação de uma comunidade política pode ser mais bem vista em Mura (2006).

${ }^{24}$ Sobre ele, ver Thomaz de Almeida (1991).

${ }^{25}$ Articulados em rede, e recentemente incluindo a Confederação da Agricultura e Pecuária do Brasil e a bancada ruralista no Congresso Nacional.

\section{Referências bibliográficas}

ARANTES, Antonio A. 2011. "Compadrio in rural Brazil: structural analysis of a ritual institution". Vibrant, 8(2):69-112.

BAILEY, Frederick George. 1971. "Gifts and poison". In: F. G. Bailey (ed.), Gifts and poison: the politics of reputation. Oxford: Basil Blackwell. pp. 1-25.

BALANDIER, Georges. 1951. "La situation coloniale: approche théorique". Cahiers Intenationaux de Sociologie, XI:44-79.

BARBOSA DA SILVA, Alexandra. 2007. Mais além da "aldeia": território e redes sociais entre os Guarani de Mato Grosso do Sul. Tese de Doutorado, Programa de Pós Graduação em Antropologia Social do Museu Nacional, Universidade Federal do Rio de Janeiro. . 2009. "Entre a aldeia, a fazenda e a cidade: ocupação e uso do território entre os Guarani de Mato Grosso do Sul". Tellus (UCDB), 9:81-104. - 2013. "Relatório circunstanciado de identificação e delimitação da T. I. Iguatemipegua I". Brasília: Funai. Mimeo.
BARBOZA, Genesio Pimentel. 1927. "Relatório apresentado ao inspetor do SPI (Antonio Martins Vianna Estigarribia) do estado de Matto Grosso". Documentação do Museu do Índio/Funai, Rio de Janeiro (Mf 341 - Fg. 1210-1249). Mimeo.

BARNES, J. A. 1987 [1969]. “Redes sociais e processo político". In: B. Feldman-Bianco (org.), Antropologia das sociedades contemporâneas. São Paulo: Global. pp. 159-193.

BARTH, Fredrik. 1966. Models of social organization. London: Royal Anthropological Institute. . 1978. "Scale and network in urban Western society". In: F. Barth (ed.), Scale and social organization. Oslo: Universitetsforlaget. pp. 163-183.

_. 1987. Cosmologies in the making. A generative approach to cultural variation in inner New Guinea. Cambridge: Cambridge University Press. - 1993. Balinese worlds. Chicago \& London: The University of Chicago Press. 
.2000a [1969]. "Os grupos étnicos e suas fronteiras". In: T. Lask (org.), O guru, o iniciador e outras variações antropológicas. Rio de Janeiro: Contra Capa Livraria. pp. 25-67.

. 2000b [1989]. "A análise da cultura nas sociedades complexas". In: T. Lask (org.), O guru, o iniciador e outras variações antropológicas. Rio de Janeiro: Contra Capa Livraria. pp. 107-139.

_.2000c [1992]. "Por um maior naturalismo na conceptualização das sociedades". In: T. Lask (org.), O guru, o iniciador e outras variações antropológicas. Rio de Janeiro: Contra Capa Livraria. pp. 167-186. 2005 [1995]. "Etnicidade e o conceito de cultura". Antropolítica, 19:15-30.

BENITES, Tonico. 2012. A escola na ótica dos Ava Kaiowá: impactos e interpretações indígenas. Rio de Janeiro: Contra Capa Livraria.

. 2014. Rojeroky Hina ha Roike Jevy Tekohape (rezando e lutando): o movimento histórico do Aty Guasu dos Ava Kaiowa e dos Ava Guarani pela recuperação de seus Tekoha. Tese de Doutorado, Programa de Pós Graduação em Antropologia Social do Museu Nacional, Universidade Federal do Rio de Janeiro.

BOISSEVAIN, Jeremy. 1966. "Patronage in Sicily". Man, I(I):18-33. 1987 [1974]. "Apresentando 'amigos de amigos: redes sociais, manipuladores e coalizões'". In: Bela Feldman-Bianco (org.), Antropologia das sociedades contemporâneas. São Paulo: Global. pp. 195-223.

BRAND, Antônio. 1997. O impacto da perda da terra sobre a tradição Kaiowá/Guarani: os difíceis caminhos da palavra. Tese de Doutorado, Programa de Pós Graduação em História da Pontifícia Universidade Católica do Rio Grande do Sul.

CAMPBELL, John K. 1977. "Honour, family and patronage: a study of institutions and moral values in a Greek mountain community". In: S. W. Schmidt; J. C. Scott; C. Lande \& L. Guasti (eds.), Friends, followers, and factions. Berkeley, Los Angeles, London: University of California Press. pp. 250-263.

ELIAS, Norbert . 1991. Qu' est-ce que la sociologie. Paris: Éditions de l'Aube.

ERIKSEN, Thomas H. 2010. Ethnicity and nationalism. New York: Pluto Press.

ESTIGARRIBIA, Antônio M. V. 1928. "Relatório da inspetoria do estado do Matto Grosso". SPI. Documentação do Museu do Índio/Funai, Rio de Janeiro. Mimeo. EVANS-PRITCHARD, Edward. 1982. "Parentesco e a comunidade local entre os Nuer". In: A. Radcliffe-Brown \& D. Forde (orgs.), Sistemas políticos africanos de parentesco e casamento. Lisboa: Fundação Calouste Gulbenkian. pp. 475-512.

FIRTH, Raymond. 1964 [1955]. "Some principles of social organization". In: R. Firth (ed.), Essays in social organization and values. London: Athlone. pp. 59-87. FOWERAKER, Joe. 1981. A luta pela terra. A economia política da fronteira pioneira no Brasil de 1930 aos dias atuais. Rio de Janeiro: Zahar Editores.

GLUCKMAN, Max. 1987 [1940]. "A análise de uma situação social na Zululândia moderna". In: B. Feldman-Bianco (org.), Antropologia das sociedades contemporâneas. São Paulo: Global. pp. 227-344.

HANNERZ, Ulf. 1992. Cultural complexity. New York: Columbia University Press.

LIMA, Antônio Carlos de Souza. 1995. Um grande cerco de paz: poder tutelar, indianidade e formação de Estado no Brasil. Petrópolis: Vozes.

MAUSS, Marcel. 1993a. "Essai sur les variations saisonnières des sociétés Eskimos. Étude de morphologie sociale". In: M. Mauss, Sociologie et anthropologie. $5^{\mathrm{a}}$ ed. Paris: Quadrige/PUF. pp. 389-477. . 1993b. "Essai sur le don. Forme et raison de l'échange dans les sociétés 
archaïques". In: M. Mauss, Sociologie et anthropologie. $5^{\mathrm{a}}$ ed. Paris: Quadrige/ PUF. pp. 145-279.

MELIÀ, Bartomeu; GRÜMBERG, Frydel \& GRÜMBERG, Georg. 1976. "Los PaîTavyterã: etnografia guarani del Paraguai contemporaneo". Suplemento Antropológico de la Revista del Ateneo Paraguayo, 9:1-2.

MINTZ, Sidney W. \& WOLF, Eric R. 1968. "An analysis of ritual co-parenthood (compadrazgo)". In: P. Bohannan, \& J. Middleton (eds.), Marriage, family and residence. New York: The Natural History Press. pp. 341-368.

MONTEIRO, John. 1994. Negros da terra. Índios e bandeirantes nas origens de São Paulo. São Paulo: Cia das Letras. MURA, Fabio. 2006. À procura do "Bom Viver": território, tradição de conhecimento e ecologia doméstica entre os Kaiowa. Tese de Doutorado, Programa de Pós Graduação em Antropologia Social do Museu Nacional, Universidade Federal do Rio de Janeiro.

MURA, Fabio \& BARBOSA DA SILVA, Alexandra. 2012. "Organização doméstica, tradição de conhecimento e jogos identitários: algumas reflexões sobre os povos ditos tradicionais". Raízes, 33(1):96-117.

OliveirA, Roberto Cardoso de. 1976. Identidade, etnia e estrutura social. São Paulo: Pioneira.

OLIVEIRA, João Pacheco de. 1988. O nosso governo: os Ticuna e o regime tutelar. São Paulo: Marco Zero/Brasília: MCT-CNPq.

- 2004. "Uma etnologia dos 'índios misturados'? Situação colonial, territorialização e fluxos culturais". In: J. P. de Oliveira (org.), A viagem da volta: etnicidade, política e reelaboração cultural no Nordeste indígena. $2^{\mathrm{a}}$. ed. Rio de Janeiro: Contra Capa Livraria. pp. 13-42.

PEREIRA, Levi M. 1999. Parentesco e organização social Kaiowa. Dissertação de Mestrado, Programa de Pós Graduação em Antropologia Social da Universidade Estadual de Campinas. PITT-RIVERS, Julian. 1976. "Ritual kinship in the Mediterranean: Spain and the Balkans". In: J. G. Peristiany (org.), Mediterranean family structures. Cambridge: Cambridge University Press. pp. 317-334. SCOTT, James C. 1985. Weapons of the weak: everyday forms of peasant resistance. New Haven and London: Yale University Press.

- 1990. Domination and the arts of resistance: hidden transcripts. New Haven and London: Yale University Press.

STOLCKE, Verena. 1982. "A família que não é sagrada (sistema de trabalho e estrutura familiar: o caso das fazendas de café em São Paulo)". In: Mariza Corrêa (org.), Colcha de retalhos: estudos sobre a família no Brasil. São Paulo: Brasiliense. pp. 39-90.

SUSNIK, Branislava. 1979-80. Etnohistoria de los Guaranies: epoca colonial. Asunción: Museo Etnográfico Andrès Barbero.

TERRA, Ademir. 2006. A modernização agropecuária de Mato Grosso do Sul: 1970-1985. Disponível em: http:// w3.ufsm.br/engrup/iiengrup/pdf/t05. pdf. Acesso em: 25/03/2016.

THOMAZ DE ALMEIDA, Rubem. 1991. O Projeto Kaiowa-Ñandeva: uma experiência de etnodesenvolvimento junto aos Guarani-Kaiowa e Guarani-Ñandeva contemporâneos do Mato Grosso do Sul. Dissertação de Mestrado, Programa de Pós Graduação em Antropologia Social do Museu Nacional, Universidade Federal do Rio de Janeiro. WEBER, Max. 1982. "Os três tipos puros de dominação legítima". In: Gabriel Cohn (org.), Max Weber: sociologia. São Paulo: Ática. pp. 128-141. . 1983 [1922]. "Comunidades étnicas". In: Economia y sociedad. Esbozo de sociologia comprensiva. México: Fondo de Cultura Económica. pp. 315-327. 
WILK, Richard R. 1984. "Households in process: agricultural change and domestic transformation among the Kekchi Maya of Belize". In: R. McC. Netting; R. R. Wilk \& E. J. Arnould (eds.), Households. Comparative and historical studies of the domestic group. Berkeley: University of California Press. pp. 217-244.

- 1997. Household ecology. Economic change and domestic life among the Kekchi Maya in Belize. Illinois: Northern Illinois University Press.

_. \& NETTING, Robert McC. 1984. "Households: changing forms and functions". In: R. McC Netting; R. R. Wilk \& Eric J. Arnould (eds.), Households. Comparative and historical studies of the domestic group. Berkeley: University of California Press. pp. 1-28.

WOLF, Eric. 1982. Europe and the people without history. Berkeley: University of California Press.

- 2003a. "Aspectos específicos dos sistemas de plantations no Novo Mundo: subculturas das comunidades e classes sociais". In: G. L. Ribeiro \& B. Feldman-Bianco (orgs.), Antropologia e poder. Contribuições de E. R. Wolf. Brasília: Editora Universidade de Brasília; São Paulo: Imprensa Oficial do Estado de S. Paulo/ Editora Unicamp. pp. 165-181.

. 2003b. "Encarando o poder: velhos insights, novas questões". In: G. L. Ribeiro \& B. Feldman-Bianco (orgs.), Antropologia e poder. Contribuições de Eric R. Wolf. Brasília: Editora Universidade de Brasília; São Paulo: Imprensa Oficial do Estado de S. Paulo/ Editora Unicamp. pp. 325-343. 


\section{Resumo}

O presente trabalho pretende analisar como são delineados processos identitários a partir das interações entre indígenas kaiowa e não indígenas no Mato Grosso do Sul. Neste proceder será considerada a relação patrão (não indígena) / cliente (indígena), lançando-se mão de uma bibliografia sobre patronagem e compadrio, considerando seus alcances e limites explicativos. Entende-se que a compreensão das relações interétnicas na região (bem como dos conflitos destas decorrentes) é beneficiária justamente de tal reflexão, que porém, até o momento, tem tido pouca atenção. Perceber-se-á que as distinções étnicas - construídas ao longo do tempo - vêm sendo reforçadas e acentuadas por processos políticos, de modo que assim nos encontramos, em alguma medida, com reflexões que já haviam sido avançadas por Max Weber.

Palavras-chave Identidade, Relações patrão (não indígena)/cliente (indígena), Conflito, Comunidade moral, Kaiowa.

\section{Abstract}

The article analyses interactions between Kaiowa indigenous people and nonindigenous people in the state of Mato Grosso do Sul, Brazil, concentrating on how they give rise to identity-building processes. It focuses on the relationship between the (non-Indigenous) patron and the (Indigenous) client, relying on the literature on patronage and compadrio, and considering its scope and limitations. It is argued that an understanding of interethnic relations in the region (as well as the conflicts arising from them) will benefit from this investigation, which has thus far been lacking. The article will show that ethnic distinctions, established over time, are reinforced and exacerbated by political processes, which brings us back to certain ideas that had already been advanced by Max Weber.

Key words: Identity, Patron/client (nonindigenous/indigenous) relations, Conflict, Moral community, Kaiowa. 